Jolie Braun

\title{
Unconventional collecting in extraordinary times \\ Documenting the pandemic through a COVID-19 Zine Collection
}

An earlier version of this article was presented as part of the 2021 Midwest Archives Conference panel "Documenting COVID-19: Successes, Challenges, and Opportunities."

W hen COVID-19 caused the world to go into lockdown in early 2020, some were inspired to create zines documenting their lives and experiences during the pandemic. That spring, The Ohio State University's Rare Books \& Manuscripts Library (RBML) began seeking out these publications, and now has a collection of more than 80 COVID-19 and quarantine zines. This article discusses how and why RBML has developed this zine collection, including the process of finding and acquiring zines, exploring their content, and plans for the collection.

\section{Background}

RBML is a special collections unit that collects, preserves, and provides access to primary source materials from medieval manuscripts to contemporary novels. Although zines had not been a collection development focus prior to my joining the unit as curator in 2016, I was excited to discover several in our holdings. A zine is a self-published, noncommercial magazine, typically inexpensively produced (often photocopied and stapled, sometimes simply printed from a home printer) in small numbers (usually ranging from a few dozen to a couple thousand copies) by one person or a small group. They can be found on any subject and often focus on niche topics.
Within a library context, zines are infinitely adaptable to class instruction, and RBML's zines have been used to explore a variety of topics, including information literacy, copyright issues, art and graphic design, rhetoric and writing, and contemporary history and social movements. Because they record voices and perspectives that may be absent from mainstream media, I see zines as an integral part of diverse and dynamic special collections. Over the past five years, I have been actively developing RBML's zine holdings, building on our existing strengths (such as LGBTQ zines and art zines), as well as expanding the collection in new directions. ${ }^{1}$

\section{Discovering "Quaranzines"}

In April 2020, I began noticing the hashtag “\#quaranzine" on social media. ${ }^{2}$ Not long after, I started to see articles about pandemic zines in major media outlets, such as Salon, Hyperallergic, and $\mathrm{NPR}^{3}$ These pieces discussed zine making as an ideal pandemic pastime: creative, therapeutic, and fun. NPR featured a step-bystep guide on how readers could make their own "mini-zine," while Hyperallergic's article included a section on quarantine zines seeking submissions. These stories were not just documenting a trend, but actively encouraging it.

Jolie Braun is curator of Modern Literature and Manuscripts at The Ohio State University Libraries Rare Books \& Manuscripts Library; email: braun.338@osu.edu

() 2021 Jolie Braun 
It was clear that many people were creating zines to reflect on, record, and share their pandemic experiences. As a special collections unit, RBML does not usually prioritize collecting materials about current events. The pandemic, however, was so significant that it seemed urgent to think about how to collect some of the many zines being produced about it.

\section{Establishing the COVID-19 Zine Collection}

Because zines are usually produced in small numbers and can quickly go out of print, that many images with this hashtag featured a unique, single item not intended for distribution or sale rather than a publication with multiple copies. ${ }^{5}$ Google searches proved more useful, often leading me directly to the website of the zine maker. I also had some success with zine distros-small vendors that sell works from a range of zine makers. ${ }^{6}$ The major resource I relied on, though, was Etsy, which allows customers to purchase directly from a zine maker. This process is unconventional, as collections are not usually created item by item, and doing so was labor-intensive. While this project likely

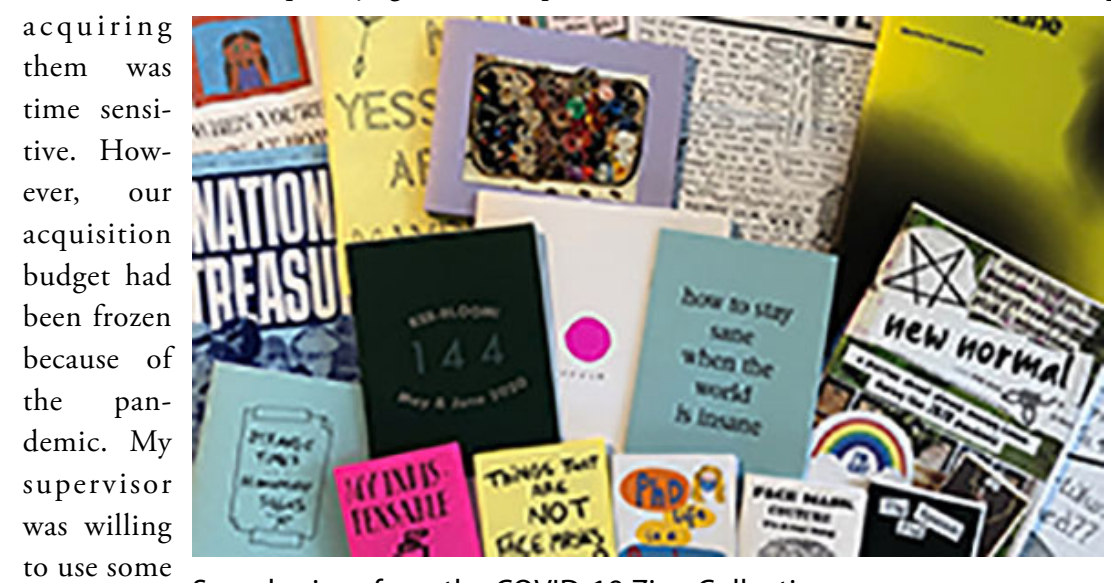

to use some of RBML's general use funds for purchasing zines. As this was an unorthodox approach, I also needed approval from the associate dean for Distinctive Collections and Digital Programs. I am grateful that they saw the value in these zines, as the project would not have been possible without their support.

I also began thinking about a collection focus. Although "quarantine zines" sounds specific, I suspected that setting some additional parameters would be helpful. I decided to prioritize nonfiction and photography and art (to complement RBML's art zines and artist's books). Geographically, I wanted to collect as broadly as possible. Lastly, I would focus on acquiring printed zines. Although there are many excellent digital zines, RBML is not yet ready to preserve and provide access to them. ${ }^{4}$

The next step was finding zines. My first stop was social media, but I only found a few available for purchase via Twitter and Instagram using "\#quaranzine." The challenge was collection development.

Before purchasing a zine, I reached out to the creator to let them know I was interested in acquiring their work for RBML's collections in case they wanted to refuse or ask questions. (None refused. Some asked questions about the collection or RBML. A few already had work in library collections, while others were surprised and delighted by the idea.)

This step was inspired by the Zine Librarians Code of Ethics, a set of recommended guidelines for acquiring zines created by group of zine librarians. ${ }^{7}$ Because zines can include personal content and most zine makers typically do not anticipate their work being preserved in an institutional collection, it is worthwhile to ask permission and give the creator the opportunity to learn more or decline.

\section{RBML's COVID-19 Zine Collection}

RBML's collection now contains more than 80 
zines, created in large part by zine makers in the United States, but other countries represented include Canada, England, France, Germany, Malta, Australia, New Zealand, and Hong Kong. All are written in English. The creators span in age from teens to 50 s. Works by veteran zine makers, as well as first-time zine makers, are included.

What are the zines like? Most are by a single creator and feature the individual's personal experiences during the pandemic. Josie Richard's Love Virus emphasizes the strangeness of the earliest phase of quarantine by juxtaposing entries on ordinary activities_-reading novels and watching old TV shows-with headlines and excerpts from news stories about the pandemic. Ciara Cordasco's Quarantimes offers "a daily account of all the non-news around the house," including headlines such as "Left Over Corned Beef for Dinner Tonight" and "Laundry Day." ${ }^{8}$ Other zines explore a writer's specific circumstances, such as Jobless at Home, which describes the zine maker's experience being unemployed during quarantine, and $P h D$ in a Pandemic, which discusses the challenges of dissertation research while libraries and archives were closed. There are also a few compilation zines that document the collective experience through many personal accounts. The U.K. zine National Treasures consists of essays by National Health Service Workers, while Pandemic Diaries, a zine by She Spends (a personal finance website for women), is comprised of reader-submitted surveys reflecting on their finances and spending habits during the pandemic.

Many of the art and photography zines capture the visible changes wrought by the pandemic. Jordan Collins's Pandemic consists of photos taken around his hometown of Toledo, Ohio, and feature a masked family at a grocery store, empty streets and parking lots, and masked participants at George Floyd protests. Catherine Aiello's Strange Times, Homemade Signs contains drawings of the handmade and often improvised signs in stores and restaurants around Somerville, Massachusetts.

In addition to the personal narratives and art zines, there are also smaller subsets within the collection. Humor zines, such as Skeletor's Guide to Self-Quarantine and Face Mask Couture, aim to provide relief from anxiety about the pandemic. Mental health and self-care zines, such as How to Stay Sober during the Pandemic, How to Stay Sane When the World Is Insane, and How to Find Inspiration during a Pandemic, offer advice on challenges that have been created or intensified by the pandemic.

\section{Conclusion}

The COVID-19 and quarantine zines in RBML's collection are an important document of life during 2020 and 2021, recording the lives of ordinary people in their own voices. The flexibility and immediacy of zines make them well suited for documenting the wide range of perspectives during the pandemic. Often featuring the zine maker's handwriting and artwork, the zines, in both form and content, emphasize humanity and individuality against a backdrop of disconnect, isolation, and breakdown in normalcy. They can be serious, humorous, anxious, hopeful, and sincere. More personal and informal than news articles, more substantial than social media posts, these zines provide a unique record that likely would not be noted elsewhere.

While there may be additions to the collection, the period of actively acquiring materials has passed. During late 2020 and early 2021, RBML's accessioning and processing coordinator accessioned many of the zines and created a preliminary inventory that is now available online. ${ }^{9}$ In spring 2021 , a selection of the zines was used in a book history class for a session about zines and community. My hope is that the collection will not only be actively used in instruction, but will also serve as a resource for researchers, the local community, and anyone else interested in understanding the COVID-19 pandemic through the medium of zines.

\section{Notes}

1. More information about RBML's collection strengths and zine holdings is available at the Collection Development page: https://library.osu.edu /rbml/collection-development.

(continues on page 361) 
Record”, BIPOC in LIS Mental Health Summit, https://docs.google.com/document/d/1FNzclS lAIVxB3CIvIjFhXqMLRi3b-xKuvtoiIqZnzrA/ edit?usp=sharing, accessed May 25, 2021.

3. BrownGirl SPACE. (2021). https://www. browngirlspace.com/. Accessed May 27, 2021.

4. Kaetrena Davis Kendrick, "LowMorale Experiences \& COVID-19 (Coronavirus)", Survey, https://docs.google.com /forms/d/e/1FAIpQLSc2ZFHFZ-HRQ2FUKrmVGK6jWtp8P6WcpSiEQtMXYJ-mHTiOvA /viewform, accessed June 28, 2021.

5. Kaetrena Davis Kendrick, et. al. pg. 1

6. Kaetrena Davis Kendrick, et. al., pg. 2.

7. Kaetrena Davis Kendrick, et. al., pg. 2.

8. Kaetrena Davis Kendrick, et. al., pg 3.

9. @AprilMuses, "BIPOC in LIS Mental Health Summit”, Twitter, https://twitter.com /AprilMuses/status/1245431221464662016, accessed May 20, 2021.

10. @Mimosaishere, "BIPOC in LIS Mental Health Summit," Twitter, https://twitter.com /mimosaishere/status/1245413713550573568, accessed May 20, 2021.
11.@BiblioXica, "BIPOC in LIS Mental Health Summit”, Twitter, https://twitter.com /BiblioXica/status/1245783243481214976, accessed May 20, 2021.

12. African American Medical Librarian's Alliance Caucus (AAMLA), "Radical Self-Care and Wellness for Information Professionals Series," AAMLA, https://sites.google.com/view/aamla-mla /events-meetings/spring-2021/radical-self-care -wellness, accessed May 25, 2021.

13. National Library of Medicine (NNLM), "Putting the Self back in Self-Care: Wellness in the time of COVID-19”, NNLM, https://nnlm.gov /class/putting-self-back-self-care-wellness-time -covid-19/24088, accessed May 25, 2021.

14. wehere, "We Got Us: BIPOC Mental Health and Solidarity," Twitter, https://twitter. com/weherespace/status/1384544864843534339, accessed May 27, 2021

15.@Kaetrena, “BIPOC in LIS Mental Health Summit: The Year in Review," Twitter, https://twitter.com/Kaetrena /status/1379252813419716622, accessed May 27, 2021. 22

("Unconventional collecting in extraordinary times," continued from page 356)

2. As of June 2021, there are more than 8,000 posts on Instagram with the hashtag "\#quaranzine": https://www.instagram.com /explore/tags/quaranzine/?hl=en.

3. Examples include Ysabelle Cheung's "Enter the 'Quaranzine': Zines That Boost Resistance, Mutual Aid, and Self-Care," April 30, 2020, Hyperallergic, https://hyperallergic.com/560443 /enter-the-quaranzine-zines-that-boost-resistance -mutual-aid-and-self-care/; Ashlie D. Stevens's "Self-Published Zines Are Back As Artists Respond to Our Reality in Quarantine," August 10, 2020, Salon, https://www.salon.com/2020/08/10 /zines-fan-magazine-comeback/; Malaka Gharib's "How to Make a Mini-Zine about Life during the Pandemic," May 28, 2020, NPR, https://www. npr.org/2020/05/28/863068957/how-to-make-a -mini-zine-about-life-during-the-pandemic.
4. Sherwood Forest Zine Library, which offers hundreds of free, downloadable zines, is one example of a resource for finding digital zines: https://www.sherwoodforestzinelibrary.org/.

5. Usually the eight-page "mini-zines" as featured in the NPR article.

6. Examples include Pen Fight Distro (https:// penfightdistro.com/) and Crapandemic Zine Distro (https://crapandemic.storenvy.com/).

7. Heidy Berthoud, et al., "Zine Librarian Code of Ethics," ZineLibraries.info (2015), https://www.zinelibraries.info/code-ofethics/.

8. Ciara Cordasco, Quarantimes 1 (2020).

9. Preliminary inventory for RBML's COVID-19 Zine Collection: https://library.osu.edu /finding-aids/ead/RARE/SPEC.RARE.0311.xml (2021). 